\section{Three New Winter-hardy Explorer Rose Cultivars}

Ian S. Ogilvie ${ }^{1}$

59 Cedar Avenue, Pointe-Claire, Quebec, H9X 4Y3, Canada

Neville P. Arnold ${ }^{1}$

Northern Hybrid Roses, 324 Edgewood, Rosemere, Quebec, J7A 3S6, Canada

Claude Richer ${ }^{2}$

Agriculture and Agri-Food Canada, Horticultural Research and Development Centre, 430 Boulevard Gouin, St-Jean-sur-Richelieu, Quebec, J3B 3E6, Canada

Additional index words. rose breeding, cold hardiness, flowering, disease resistance, Rosa $\times$ kordesii

Three new winter-hardy rose cultivars of hybrid origin belonging to Explorer Cultivargroup are on the market: 'AC De Montarville', 'ACMarie-Victorin', and 'AC William Booth'. They flower repeatedly from June to September, and are resistant to powdery mildew [Sphaerotheca pannosa (Wallr. ex Fr.) Lev.]. 'AC De Montarville' is tolerant to blackspot Diplocarpon rosae Wolf. in Canada or in U.S. Dept. of Agriculture (USDA) hardiness zones 2 to 5, and 'AC Marie-Victorin' and 'AC William Booth' are resistant to blackspot at Ottawa, Ont., and at L'Assomption, Que., Canada.

'AC De Montarville' is a medium-sized, erect, shrub rose with medium-red flowers. This shrub resembles 'Champlain' or 'Frontenac' rose in the time of bloom but is superior to both in floral production. 'AC Marie-Victorin' is an erect, large shrub with peach-colored flowers, a color rarely found in hardy roses. 'AC William Booth' is a spreading type with medium-red flowers; although single-flowered, it has higher floral production than any Explorer Cultivar-group registered and will be designated as an official rose for the Salvation Army organization. Both 'AC Marie-Victorin' and 'AC William Booth' have excellent resistance to severe winter temperatures and common rose diseases.

\section{Origin}

'AC De Montarville'. This cultivar was derived from a cross between A15, a semihardy low-growing shrub, and L76, a hardy pink shrub (Fig. 1). The seed parent was derived from a cross between 'Queen Elizabeth'

Received for publication 22 June 1998. Accepted for publication 2 Nov. 1998. The cost of publishing this paper was defrayed in part by the payment of page charges. Under postal regulations, this paper therefore must be hereby marked advertisement solely to indicate this fact.

${ }^{1}$ Retired Researcher.

${ }^{2}$ Research Scientist, Agronomist, to whom all correspondence should be addressed.
(Grandiflora Cultivar-group) and 'Arthur Bell' (Floribunda Cultivar-group). The pollen parent, L76, is a complex hybrid. It originated from a cross between a) one line resulting from hybridization of Rosa $\times$ kordesii Wulff with a seedling originating from a cross between 'Masquerade' and a pink form of $R$. corymbifera Borkh. 'Laxa' (Beaudoin, 1997) and $b$ ) another line derived from a cross between the 'Red Pinocchio' (Floribunda Cultivar-group) and a hybrid between the 'Joanna Hill' (Hybrid tea Cultivar-group) and the species rose $R$. pimpinellifolia L. 'Grandiflora'. The high degree of winter-hardiness is derived from $R$. ×kordesii, $R$. corymbifera, and $R$. pimpinellifolia, the latter two being hardy species from northern Europe and Asia (Svejda, 1988). This rose was named in honor of the founder of the town of St-Bruno de Montarville, Que.

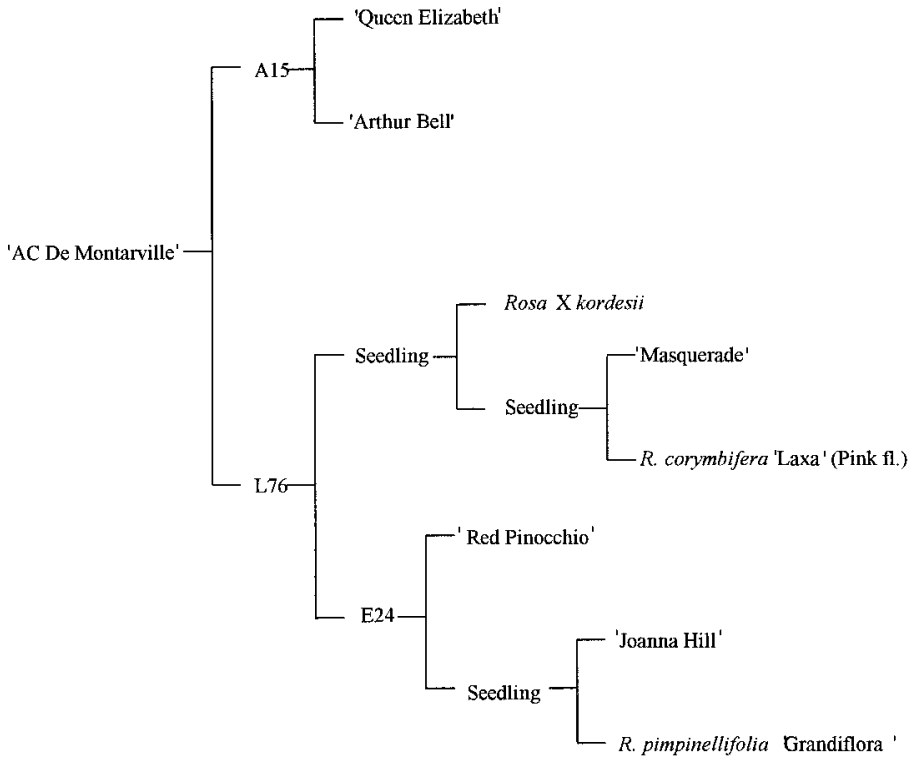

Fig. 1. Pedigree of rose 'AC De Montarville'.

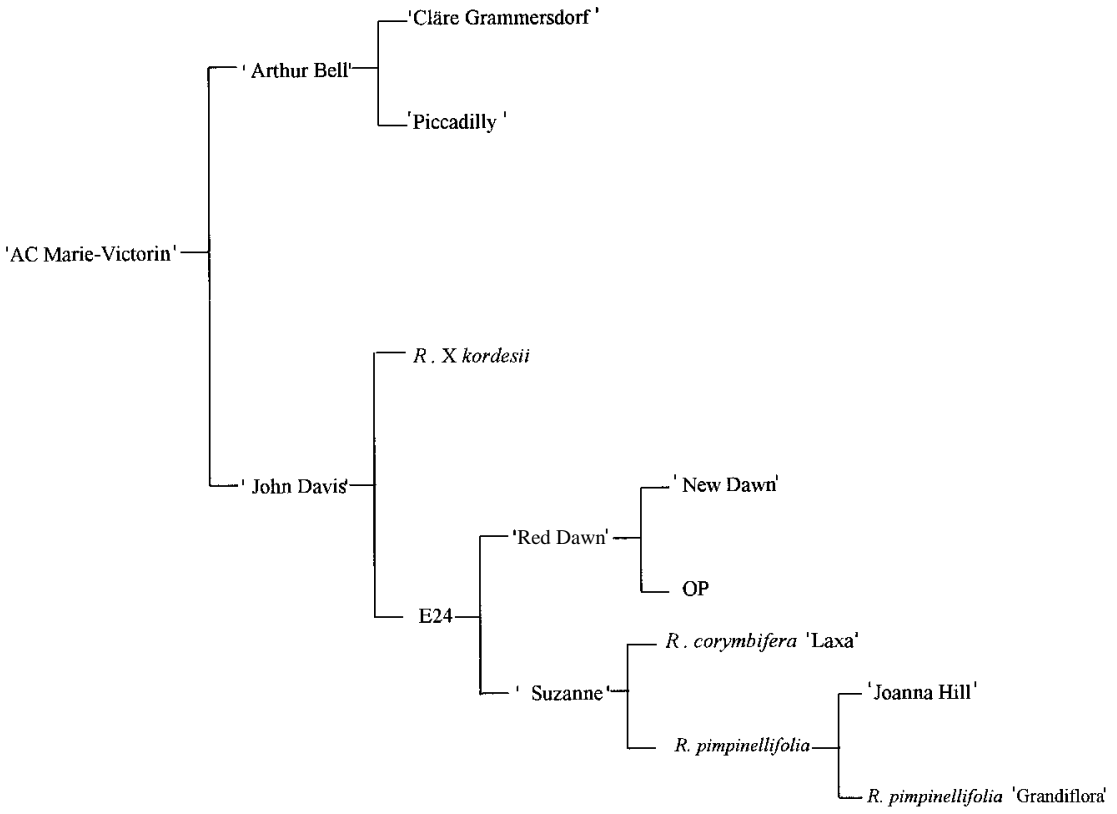

Fig. 2. Pedigree of rose 'AC Marie-Victorin' (OP indicates open pollination). 


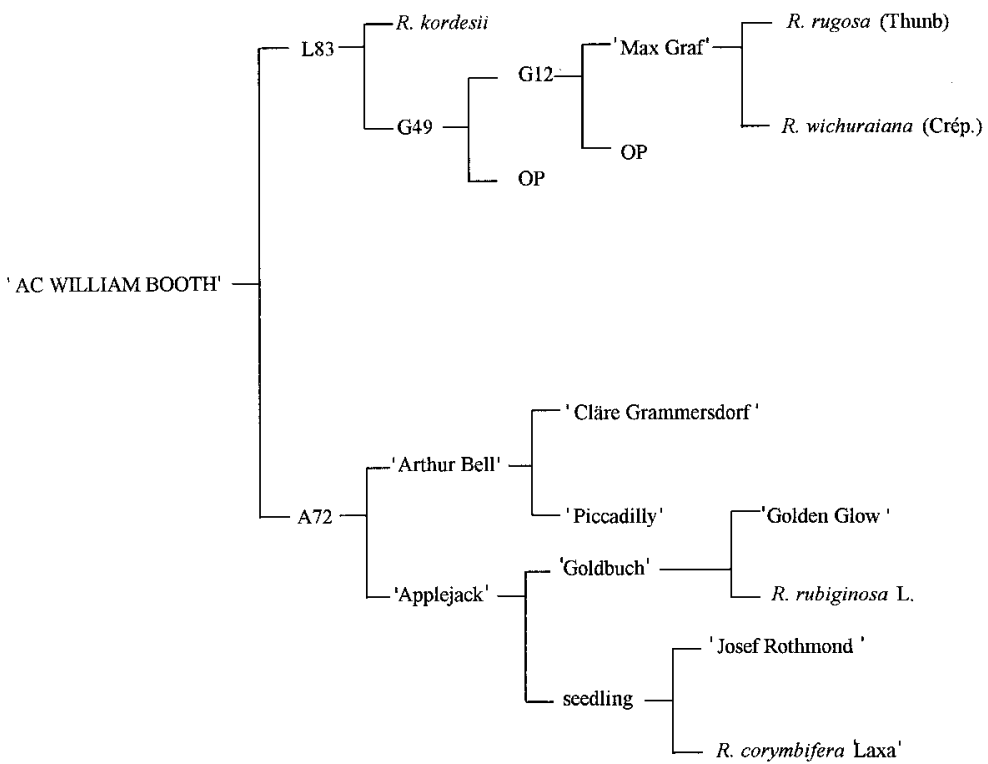

Fig. 3. Pedigree of rose ‘AC William Booth' (OP indicates open pollination).

'AC Marie-Victorin'. This cultivar arose from a cross between 'Arthur Bell' and the hardy 'John Davis' (Explorer Cultivar-group) (Fig. 2). The seed parent was derived from a cross between 'Cläre Grammersdorf' (Floribunda Cultivar-group) and 'Piccadilly' (Hybrid-tea Cultivar-group). The pollen parent, 'John Davis', was derived from pollination of $R$. $\times k$ kordesii by $\mathrm{D} 08$, a hybrid derived from 'Red Dawn' and 'Suzanne' (both Shrub Cultivar-group). 'Suzanne' is a hybrid of $R$. corymbifera 'Laxa' and $R$. pimpinellifolia. The high degree of winter-hardiness is again derived from $R$. $\times$ kordesii, $R$. corymbifera 'Laxa', and $R$. pimpinellifolia. This rose was named in honor of the founder of the Montreal Botanical Garden.

'AC William Booth'. This cultivar was derived from a cross between L83 (Svejda, 1988), a line derived from $R$. $\times k o r d e s i i$, and the breeding line A72 (Fig. 3). The seed parent resulted from a cross between $R$. $\times k$ kordesii and breeding line G49. G49 was obtained by openpollination of a tetraploid seedling, G12, which in turn is a seedling of the usually sterile 'Max Graf' (Shrub Cultivar-group). The pollen parent, A72, originated from a cross between the floribunda 'Arthur Bell' and the shrub rose 'Applejack' (Shrub Cultivar-group). The high degree of winter-hardiness is derived from $R$. $\times$ kordesii and $R$. corymbifera 'Laxa'.

\section{Description}

Color designation of flowers, stems, and foliage follow the Royal Horticultural Society (1966).

'AC De Montarville'. This cultivar has an upright type growth habit such that branches of 5-year-old plants reach $1 \mathrm{~m}$ in height with a spread of $1 \mathrm{~m}$ at L'Assomption (Fig. 4A). The young shoots have weak reddish-brown coloration. The prickles (four to five per $100 \mathrm{~mm}$ of stem) are short, infrequently elongate, deeply concave, and reddish-brown. Leaves are abundant, leathery, medium green (147A), and glossy above, with three to five leaflets. Leaflets are ovate, acuminate, dentate, 27 to $35 \mathrm{~mm}$ long, and 15 to $23 \mathrm{~mm}$ wide, green (137A) above and yellow-green (147B) below. Inflorescences bear clusters of one to four flowers. Flowers are 68 to $72 \mathrm{~mm}$ in diameter with 23 to 29 petals. The upper and lower petal surfaces are reddish-purple (67C) with a yellowgreen basal spot (7B). The dark red (63A) unopened bud changes to a medium pink (58A) at the blossom stage, and later fades to a medium mottled pink (55A) in the fully opened flower.

'AC Marie-Victorin'. This shrub has an arching growth habit such that branches of 5year-old plants reach $1 \mathrm{~m}$ in height with a spread to $1.5 \mathrm{~m}$ at L'Assomption, Quebec (Fig. 4B). The young shoots have a strong bronze coloration. The prickles ( 8 to 12 per $100 \mathrm{~mm}$ of stem) are short to long, deeply concave, and dark brown. Leaves are abundant, leathery, medium-green (137A), strong glossy above, and bear five to seven leaflets. Leaflets are ovate, cordate, acuminate, dentate, 38 to $50 \mathrm{~mm}$ long, 29 to $38 \mathrm{~mm}$ wide, green (137A) above, and yellow-green (147B) below. Inflorescences bear clusters of one to seven flowers. Flowers are 85 to $90 \mathrm{~mm}$ in diameter with 34 to 42 doubled petals with a normal center and exhibiting a prominent yellow (10D) eye-spot. Flowers are round when viewed from above, with a flat upper and lower part when viewed laterally. The sepal extensions are weak. The floral bud is acute in longitudinal section, a blend of rose (58B) changing to a pale peach (55A) at the blossom stage, later fading to a pink (56D) in the fully opened flower. The outer stamens have a yellow filament. The style is short, with medium pubescence on the upper half. The stigma is positioned below the anthers. The receptacle is small, pear-shaped, and bears prickles.

'AC William Booth'. This shrub has a trailing growth habit such that branches of 5-yearold plants reach $1.5 \mathrm{~m}$ in height with a spread to $2.0 \mathrm{~m}$ at L'Assomption (Fig. 4C). The young shoots have a very strong purple coloration. The prickles ( 8 to 12 per $100 \mathrm{~mm}$ of stem) are long, infrequently short, deeply concave, and red-brown. Leaves are abundant, leathery, dark green (147A), and very glossy above, with five to seven leaflets. Leaflets are ovate, round, acuminate, dentate, 32 to $60 \mathrm{~mm}$ long, 22 to $43 \mathrm{~mm}$ wide, with red-purple expanding leaves (59A) when juvenile, becoming green (147A) above, and yellow-green (148A to 147C) below with age. Inflorescences bear clusters of eight to 10 flowers. Flowers are 48 to $53 \mathrm{~mm}$ in diameter with five petals, each bearing a white eye-spot basally and exhibiting some reflexing and undulation. The floral bud is acute in longitudinal section, deep red (57A) when unopened, changing to a medium red $(57 \mathrm{~B})$ at the blossom stage, and later fading to a light red (57C) in the fully opened flower.The outer stamens have a yellow filament. The style is short with a weak pubescence on the upper half. The stigma is positioned below the anthers. The receptacle is small, pear-shaped, and bears prickles.

These cultivars bloom continuously for more than 10 weeks. 'AC De Montarville' has low female fertility and flowers only occasionally form fruits (hips) under open pollination. The fragrance of both 'AC MarieVictorin' and 'AC William Booth' flowers is weak. Both cultivars are female-fertile, and most flowers form fruits (hips) under open pollination.

\section{Performance}

'ACDe Montarville', 'ACMarie-Victorin', and 'AC William Booth' have been tested at Ottawa for 2 years (1985 to 1987) and for an additional 3 years at L'Assomption (1988 to 1991). Both sites are in the Canadian plant hardiness zone 5a (Ouellet and Sherk, 1967) or USDA zone 4, (Cathey and Heriteau, 1990). Also, 'AC Marie-Victorin' was tested in eight locations for 5 years in the principal growing region of Quebec, with a zonal range covering 2 to $5 \mathrm{~b}$ in the Canadian system (Richer et al., 1995). These roses have survived test winters to $-35{ }^{\circ} \mathrm{C}$ without protection (except natural snow cover) and have shown only slight tip kill on younger shoots. 'AC Marie-Victorin' exhibited slight winter injury in zones 4 and 5 and older stems have exhibited winter damage in zone 2.

These roses are propagated easily when softwood cuttings are taken at the bud stage and dipped in rooting powder (Stimroot \#2, $0.4 \%$ indolebutyric acid; Plant Products, Bramalea, Ont.), then placed under mist for 3 to 4 weeks. These three new Explorer roses must be grown on their own roots.

\section{Availability}

All three cultivars have been protected with the Plant Breeders Right Office since 1997 and registered with the Canadian Ornamental Plant Foundation (COPF), P.O. Box 21083, North Bay, Ontario, P1B 7N8, Canada. Royalties will be collected. Limited amounts of propagation stock are available to licensees. 


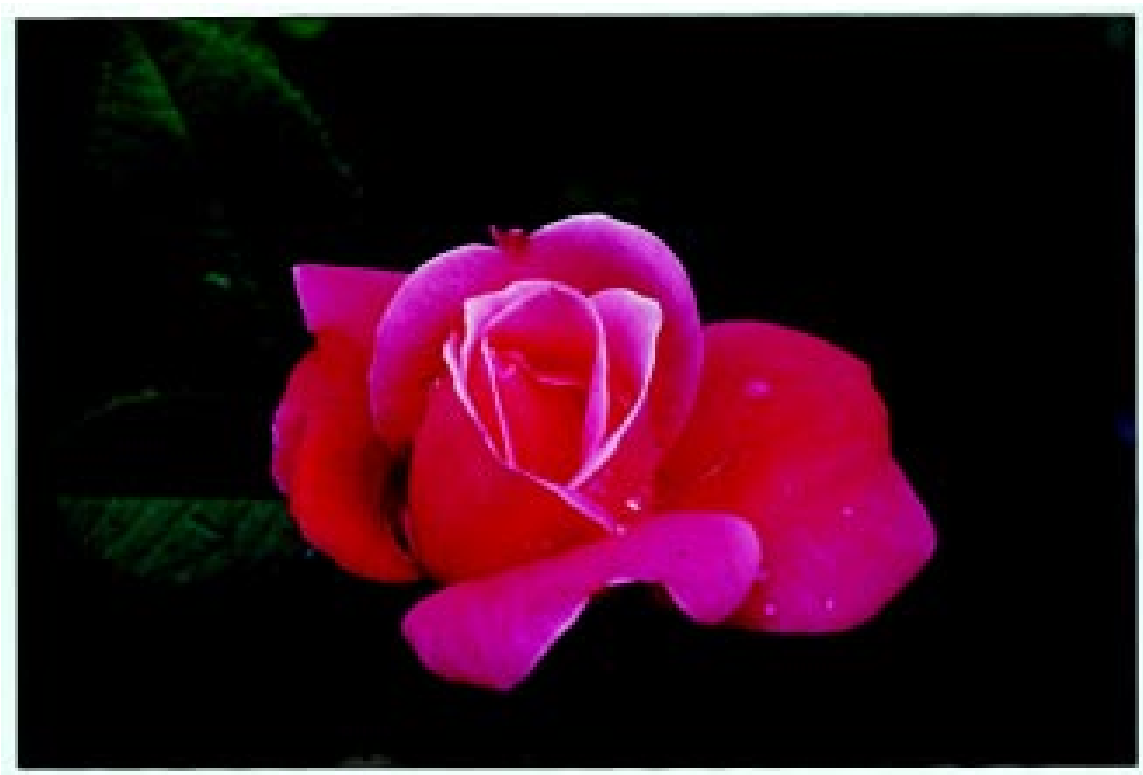

'AC De Montarville' was released on the market in 1997 and 'AC Marie-Victorin' in 1998. Plants of 'AC William Booth' will be released in 1999. Address American commercial requests to Bailey Nurseries, 1325 Bailey Rd., St. Paul, MN 55109.

\section{Literature Cited}

Beaudoin, M.F. 1997. Lexique des plantes ligneuses ornementales du Québec/Index of Ornamental Woody Plants of Quebec. CPVQ. 185 p.

Cathey, H.M. and J. Heriteau. 1990. Mapping it out. Amer. Nurseryman 171(5):55-63.

Ouellet, C.E. and L.C. Sherk. 1967. Map of plant hardiness zonation in Canada. Can. Dept. Agr. Publ. 5003.

Richer, C., J.A. Rioux, and J. Coté. 1995. Rusticité et croissance de plantes ligneuses ornementales au Québec. Vol II. Conseil des productions végétales du Québec. 468 p.

Royal Horticultural Society. 1966. Royal Horticultural Society Colour Chart. Royal Hort. Soc., London.

Svejda, F. 1988. Rose germplasm L83. HortScience 23:41-46.
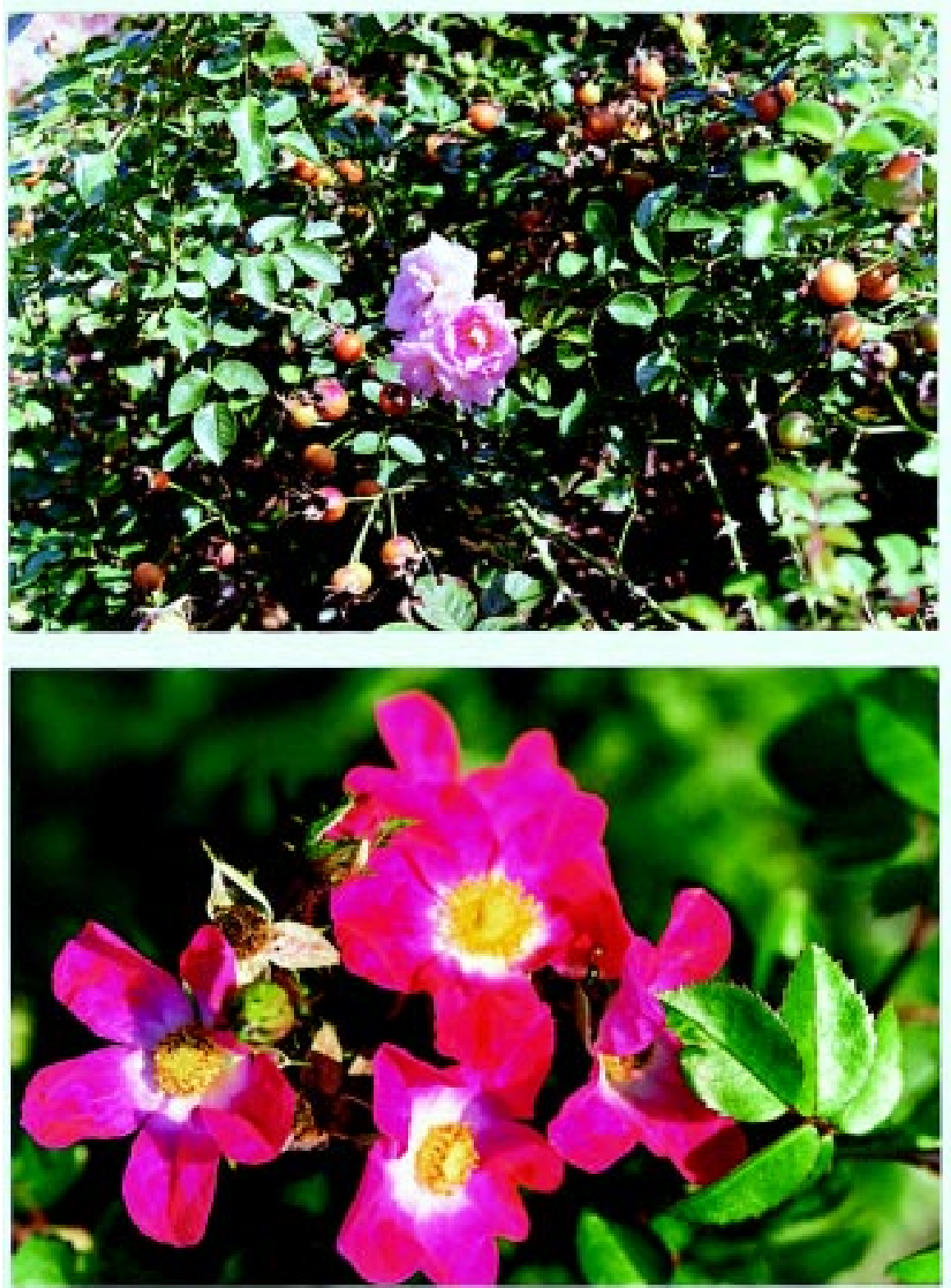

Fig. 4. The winter-hardy shrubs roses (A, top) 'AC De Montarville', (B, middle) 'AC Marie-Victorin, and (C, bottom) 'AC William Booth'. The plants are (A) 1.0, (B) 1.5, and (C) $2.0 \mathrm{~m}$ wide. 